\title{
MÁRIO DE ANDRADE E UMA CARTA
}

Em setembro de 1944, Mário de Andrade veio mais uma vez a Belo Horizonte. Já viera a Minas em várias ocasiões, detendo-se nas chamadas cidades históricas, para estudo da arte colonial, editados com pioneirismo em famoso texto de 1928 - O Aleijadinho e sua posição nacional, reeditado em 1935 em $O$ Aleijadinho e Alvares de Azevedo. Gostou de Belo Horizonte desde a primeira visita, como se vê pelo poema que lhe dedicou e é ponto alto de sua poesia - "Noturno de Belo Horizonte", de 1924. Voltou algumas vezes.

A última foi em setembro de 1944, quando esteve muitos dias no Grande Hotel, a casa famosa da rua da Bahia que tanto marcou a política e a literatura dos anos vinte e trinta. Em 1924, era visitado pelos moços escritores de então, Carlos Drummond de Andrade, Emílio Moura, Martins de Almeida, Pedro Nava, João Alphonsus e mais outros, formadores do chamado grupo modernista 
mineiro, de tamanha importância na literatura do país, como se via pelas revistas e jornais que faziam na Provincia e pelo que editavam, em jornais do Rio e São Paulo, estourando em livros nos anos trinta.

A década de quarenta era menos livre, mais abafada que as anteriores, com o Estado Novo no plano nacional e o facismo e a guerra no internacional. Se a de vinte fez o modernismo, comemorando o primeiro centenário da Independência, fez mais ainda, dando início ao ciclo de contestações da ordem política com o episódio de 1922 e o forte de Copacabana, 1923 no Rio Grande do Sul, 24 em São Paulo, depois a Coluna Prestes até 1927 , culminando com a revolução de 30 , no processo que se chamou de Revolução Brasileira cada um dos movimentos é simples constatação, o conjunto pode ser visto como Revolução, processo iniciado e ainda em marcha, tímida e hesitante, com avanços e recuos, como se nota ainda hoje no quadro confuso que se vive.

Assistiu também à Semana de Arte Moderna, significativamente no ano do centenário, que provocou mais ainda, com início da atuação ideológica, a emergência da direita e da esquerda, nos padrões comuns do mundo de então, com a maior atividade da direita, pelo facismo começado na Itália, ou pelo radicalismo esquerdista da revolução russa de 1917, que instaura o primeiro governo comunista de grande vulto, com tendências confirmadas no Brasil com a criação da revista $A$ Ordem, em 1927, e do Centro Dom Vital, em 1922, alerta de consciência católica para participação mais efetiva, bem como do Partido Comunista do Brasil, no mesmo ano.

A política superava o simples jogo de interesses imediatos para enveredar pela disputa ideológica, relativa novidade na terra desencantada com a política republicana e exigente de outra ordem. As disputas entre guerras 1919-1939 culminam com a guerra que se arrastará de 1939 a 1945. O debate ideológico empolgava as consciências. A guerra na Europa, com certa participação brasileira, emocionava os jovens, dividindo-os em grupos. Era vivo o debate, nos setores intelectuais, sobre a literatura engajada, se o escritor deve participar da política ou manter-se distante, na célebre torre de marfim. As posiçōes se acirravam.

Mário de Andrade foi um dos seus agentes mais ativos, como se vê em muitos de seus importantes escritos - como na conferência "O Movimento Modernista", de 1942. Durante sua presença em Belo Horizonte as visitas ao Grande Hotel se sucediam. Toda noite ali se encontravam os mais jovens, dedicados à literatura, não só pela admiração pelo escritor, como por sua fama de generoso acolhimento. $\mathrm{O}$ homem famoso a todos recebia, com a mesma lhaneza e atenção. Escutava seus problemas, aconselhava leituras, fazia amizades. Com alguns já se correspondia. Mário terá sido das pessoas que mais escreveram cartas. Tanto ou mais do que Flaubert. Nunca deixou ninguém sem resposta, ouvindo e dialogando, sem jamais adotar o tom professoral. Conversava sempre como entre iguais.

$\mathrm{Eu}$, pouco passando dos vinte anos, cometia meus artigos, publicando-os em jornais de Belo Horizonte e $\operatorname{logo}$ depois no Rio e em São Paulo. Os dois primeiros apareceram no jornal literário Dom Casmurro, dirigido por Brício de Abreu, no Rio de Janeiro; um sobre a poesia do baiano Odorico Tavares, outro sobre Vinicius de Morais. Não seria crítico literário, no entanto, enveredando antes por uma pretensa crítica de idéias.

Enquanto Mário descansava em Belo Horizonte, em intermináveis conversas de bar e em noitadas em geral concluídas em um banco da Praça da Liberdade, publiquei um artigo em $O$ Diário, de 10 de setembro de 1944 ("Nota Inicial", em parte sobre suas recentes posições), que mereceu comentários favoráveis da figura admirada e querida. Anos depois, em 12 de junho de 1949, em A Ma$n h \tilde{a}$, do Rio de Janeiro, escreveria sobre o próprio Mário, artigo intitulado "Elegia de Abril", nome usado por ele mesmo em ensaio famoso sobre os compromissos do escritor com a sociedade, título também usado em livro de poesia do mineiro Cristiano Martins, que se escondeu no pseudônimo de Marcelo de Sena. 
E logo Mário voltou a São Paulo. Muitos daqueles jovens se encontrariam com ele em janeiro, naquela cidade, quando da realização do I Congresso Brasileiro de Escritores, do qual Mário foi, embora sem querer, uma das figuras centrais. Vencendo a natural timidez - começava a sua superação - , fui e visitei-o depois do Congresso. Convidou-me para almoço em sua casa, no famoso endereço da rua Lopes Chaves, almocei com a familia. Presente também o poeta Paulo Armando, jovem admirador de Mário de passagem pela cidade - bem falante e extrovertido. Depois do almoço saímos.

Mário mostrou-nos uma de suas criações que mais orgulho lhe davam - a Discoteca Pública do $\mathrm{Mu}$ nicípio, no porão do Teatro Municipal, feita quando dirigiu o Departamento de Cultura, um momento na história da administração pública. Era dirigida por uma de suas alunas diletas - a musicóloga mineira Oneyda Alvarenga.

Voltei a Belo Horizonte, no princípio do ano já recebera a sua carta - longa e afetuosa, encorajadora: sua letra não era de fácil leitura, exigia decifração. Incrivel que um homem tão importante se desse ao trabalho de responder a uma carta de jovem sem qualquer importância e que nada tinha a dizer. Era datada de 2 de janeiro de 1945. Foi uma das maiores emoções que até então experimentara. Pouco depois, no dia 25 de fevereiro, Mário morria fulminado por uma angina. Provavelmente, recebera a minha resposta. Era moço de 51 anos apenas. Morreu precocemente, deixando vasta obra, que ainda tinha muito a dar para a cultura de seu país e na direção da vida literária. Quem teve a bem aventurança de conhecê-lo jamais o esqueceu ou viu diminuida a velha admiração. Logo depois de sua morte, entrou em certa sombra, da qual emergiu cerca de vinte anos depois, cumprindo certa lei da sociedade da arte, sobretudo por causa de Macunaíma, pela adaptação feliz para o palco e para o cinema pelos diretores Antunes Filho e Joaquim Pedro de Andrade. E está cada vez mais vivo e presente. Agora já um nome definitivo, convencionalmente julgado pelo tempo. O subversivo dos anos vinte hoje é um clássico. E eu conservo com carinho a sua carta, certo de que teria agora não uma e sim dezenas, pois também sou dado à epistolografia.

São Paulo, 2-1-45.

\section{Meu caro Iglésias}

Recebi sua carta boa e eu creio mesmo que mandei avisar você que só lhe respondia "o ano que vem", que é este chegado e eu desejo bom pra você e esta nossa humanidade. Realmente tive um dezembro com excesso de trabalho, terminação de tarefas de ano, desta vez até um bocado angustiosas, coisas que estavam me chateando, umas por prolongadas demais, outras porque não gostava muito delas. Agora estou mais livre, pelo menos que eu chamo a minha liberdade, liberto de encomendas, cheio de trabalhos mas que são os trabalhos que eu quero e escolho, meus. Ponho no meio deles o escrever cartas aos amigos, e a primeira que escrevo neste 45 é esta para você. Este ano vou dar um bom espaço pras cartas, me sinto tão vivendo e feliz dentro delas. Ah, se eu conseguisse escrever artigos com a facilidade e a isenção de espírito com que escrevo cartas. Muitas destas me saem artigos alentados no tamanho e escoam fáceis em pouco tempo. Mas é raro o artigo de quatro páginas datilografadas que não tome várias horas. E não pense que é porque sejam muito trabalhados não, é qualquer coisa que me entorpece o pensamento, não sei, um temor e um desgosto. Paro, não consigo ir para diante, não tenho idéias, o espaço me angustia. Realmente não gosto de escrever artigos para jornal, não sou homem de artigos. O ensaio sim, o estudo pra revista ou livro em que posso me esparramar, isso é mais comigo. $\mathrm{E}$ as cartas.

No momento me sinto satisfeito ao possível comigo. Terminei uma monografia para o Serviço do Patrimônio, sobre um tal de "Padre Jesuino do Monte Carmelo", um pintor paulista do séc. XVIII, e um ensaio sobre o pintor Clóvis Graciano. Arre que terminei esse danado de 44 , sinão com chave de ouro, ao menos com as minhas chaves possíveis. Ano ruim e infrutifero de trabalho 
pra mim, esse 44. Andei pegando encomendas que não eram bem minhas e me encalharam no caminho. Uma espécie de falso alarma da celebridade me deixou imodesto e um bocado esquecido de mim. Também tinha sofrido tanto com doenças em 43, e o ano principiou tão incerto pra mim, que me esqueci de me dar uma tarefa bem firme pro ano todo em janeiro passado. E como vinham encomendas que rendiam, fui me deixando levar ao léu dos interesses dos outros, e me esqueci de continuar a construção da casa. Mas agora gritei um "independência ou morte" que não sinto egoísta, porque afinal eu assim é que dou o quanto posso dar. Me dei uma tarefa como sempre costumava fazer, antes que a esquina grande e torva da minha vida me atirasse sem eira nem beira morando no Rio de Janeiro. Este ano vou escrever dois ensaios longos, cada um deles deve dar um livro aí de duzentas páginas cada, "O Sequestro da Dona Ausente" e a "Música de Feitiçaria no Brasil". Vai ser ano de folclore como você está vendo. Além disso tenho que escrever a Introdução, pro $1 \underline{0}$ vol. das Obras Completas, em que pretendo descrever a minha experiência de poesia, uma espécie de ensaio sobre o meu processo de criação poética. Ou melhor: como a criaçāo poética se processa em mim. Não dou muita importância a ... a mim, acredite, minha obra é toda muito utilitária e de interesse de combater coisas ou por coisas, pra que eu possa lhe dar muita garantia de valor permanente. Mas é por isto mesmo que me parece de interesse aos outros uma análise da criação justamente mais livre, que é a da poesia, numa obra tão voluntariosa e predeterminada. Já, embora timidamente, os superticiosos da "expontaneidade" têm me acusado de insincero, no sentido de fazedor penoso de poemas. E o mais curioso é que às vezes mesmo um amigo íntimo de repente reconhece com exclamações que a minha poesia é livre e sincera. $\mathrm{O}$ que prova que mesmo a ele o problema de uma possível insinceridade minha tinha já se imposto. Eu creio porisso que por os pontos nos ís e esclarecer esses conceitos tão confusionistas de expontaneidade, sinceridade, liberdade da criação poética não é fora de tempo.
Estou me deixando muito de propósito falar de mim porque os pontos em que toquei podem lhe ser úteis, Iglésias, e eu desejo que você utilize como e todas as vezes que quiser, o que eu tenho de melhor, uma longa e muito refletida experiência. Não sei si é por ter um temperamento naturalmente religioso, mas o que eu mais transportei das religiões para dentro da minha vida pessoal são os ritos. Eu desconfio que os expontâneos ainda não calcularam bem a importância fecunda dos rituais. Bem, eu sei que quando os ritos se transportam para a vida pessoal, nós lhes damos o nome-feio de métodos. "Fulano é metódico" e "Sicrano tem muito método". Mas eu faço questão do rito, os métodos variam e não implicam a realização do digamos, ato sacramental. Eu sempre tive apenas um método e este variou com as circunstâncias. Mas em compensação tive uma vida muito ritualizada, tarefas ânuas, mensais, horas certas pra fazer cada coisa, até pra me divertir. Aliás mesmo no passeio de Belo Horizonte, talvez você tenha reparado isso. Vivi dentro dum ritual que me libertou extraordinariamente de horas vazias, de desperdício, de prazeres falsos, e me permitiu ser profundamente feliz.

Sua carta ainda, por ser decerto a primeira, ainda não penetrou diretamente num problema definido que implica resposta. Mas entre as coisas firmemente pensadas dela, quero levantar principalmente uma frase. É aquela em que você diz d"o exemplo mais alto do que é uma existência de homem de estudo, de artista, de ação, ou de homem, simplesmente". A ressalva final é que me agradou muito, assim concluída por você mesmo. Nestes tempos difíceis em que o déficit da sociedade humana está impondo excepcionalmente ao artista, ao cientista, os seus deveres de "homem, simplesmente", o de participar também com a sua arte ou seus estudos do combate humano, está se alastrando uma noção esperta, inventada pelos que uma covardia, uma preguiça ou um egoismo impedem de participar. São às centenas os que dizem "sou homem de ciências e o laboratório é o meu lugar" e que por isso deixam de ser "homem, simplesmente" e aplaudem esse ditador, e aceitam um convite de Hitler. $\mathrm{Na}$ arte então quantas vezes 
não tenho ouvido e lido os que dizem que "como homens combatem o fachismo, mas como artistas não cogitam disso". Não querem "conspurcar" a pureza da arte, como si a arte fosse mais pura que "o homem, simplesmente", e conspurcam o homem!

Só existe uma coisa, Iglésias, e você tem razão: é o homem, simplesmente. Ninguém é em dois homens, o artista e o homem. Tudo é um só, e o artista, o cientista, não é sinão uma qualificação profissional do homem. E uma qualificação jamais desclassificou o homem. E esse hiperindividualismo do artista e do cientista é uma invenção recente. Alguns dos tortuosos separadores do homem do artista não deixam de perceber a falcatrua que fazem de si mesmos... Ainda hoje de-manhã, classificando uns papéis e fichas pra um estudo sobre Chostacovich que devo fazer esse janeiro, ainda me caiu nos olhos a argumentação dum desses artistas puros. Muito inteligente e de bastante valor, por sinal. Como é que ele argumentava? Não vou buscar o texto dele, não importa, o que importa é o advérbio. Ele dizia que querer fazer da arte "permanentemente" uma arma de combate era conspurcá-la. Você está vendo? Quem disse o "permanentemente", sinão ele, pra poder estar com alguma razão? Eu jamais me recusarei um poema sobre a primavera ou um estudo sobre um pintor do séc. XVIII, simplesmente porque isso faz parte do "homem, simplesmente". E é por isso que não me recuso um poema de combate, uma sátira, um artigo que envenena ou destrói, porque isso faz parte do "artista, simplesmente".

Eu sei: é muito mais fácil (embora não mais sincero) me sair um poema de amor ou sobre o pássaro morto. Mas isto, essa facilidade, essa expontaneidade, não é sinão um defeito, uma precariedade da minha educação. E quem me deu essa educação, fui eu? Quem escolheu essa educação, fui eu? Não fui, com mil bombas. Foram meus pais, foram meus colégios, coitados, acredito que quase todos eles na melhor das intenções. Mas todos eles foram feitos, afeitos e contrafeitos por uma sociedade errada que os organizou e escravizou e mandou. $\mathrm{O}$ que me cabe a mim como homem pra me qualificar de artista verdadeiro, artista de mim mesmo, é me reeducar. É enfim escolher pra poder ser eu. Mas a maioria infinita em vez de escolher pela inteligência e a vontade inteligente, se deixa levar pelo gozo das suas tendências. Mas si estas tendências não são dele! Si elas têm dois séculos de herança por detrás! Na verdade, Iglésias, o mundo está completamente cheio de expontâneos e é por isso que vai tão indigno e tão aviltado.

Agora vou parar que já tive uma conversa boa com você. Me escreva quando e quanto quiser. Me conte em principal na sua próxima carta o que você prefere e pretende ser em sua vida. Não sei, mas você tem jeito de ensaísta. A sua carta demonstra um pensamento nutrido, sensivel às nuanças das idéias, atento ao valor das palavras. Mande contar pra ver no que eu posso lhe se de algum auxílio. Nosso contacto não foi dos mais prolongado aí em Belo Horizonte, e nas chopadas você ficava sempre longe. Não estou censurando, não faz mal. Mas eu apreciava sempre quando uma observação sua entrava na conversa. E eu sei que poderemos ser bons amigos, esquecidos, sem normas de boa-educação, sem "estilo epistolar", nos falando mais intimamente de nós. Como eu fiz nesta. Me lembre a todos os amigos d'aí e guarde o abraço mais sincero do

Mário de Andrade

Nota da Redação: Foi mantida a ortografia original do escritor $e$ atualizada a acentuaçāo. 


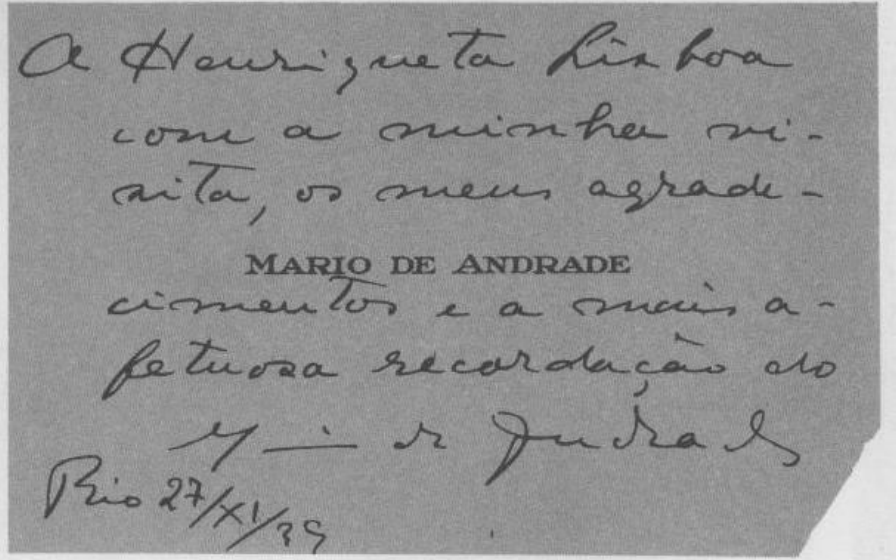




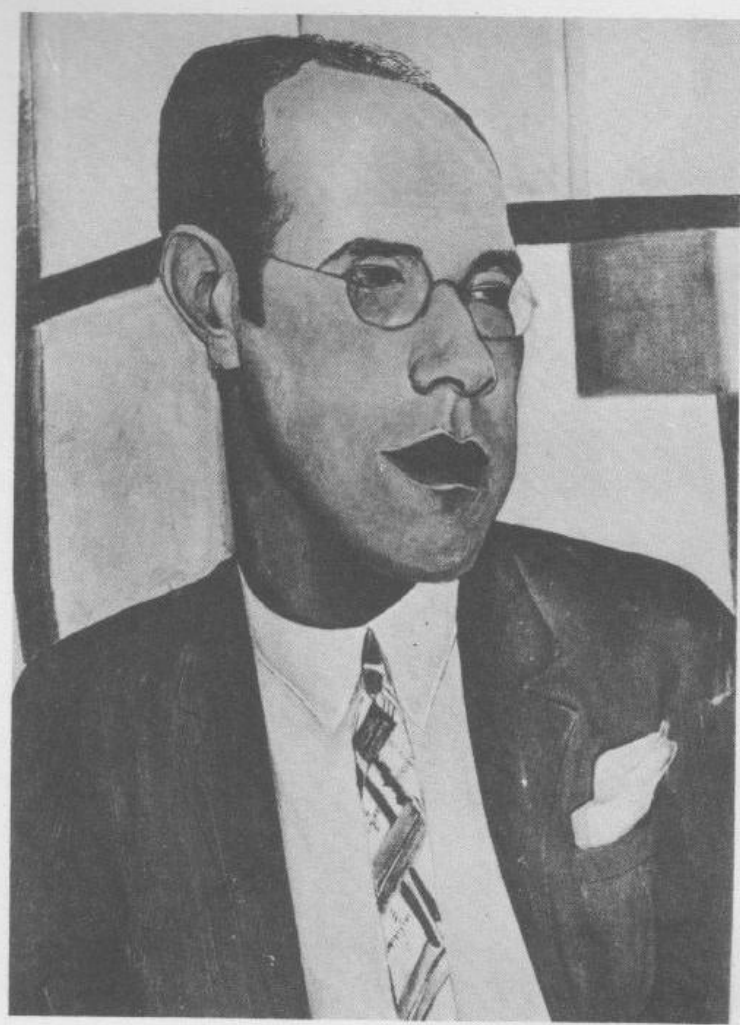

Mário de Andrade

Óleo de Laser Segall - 1927

IEB - USP

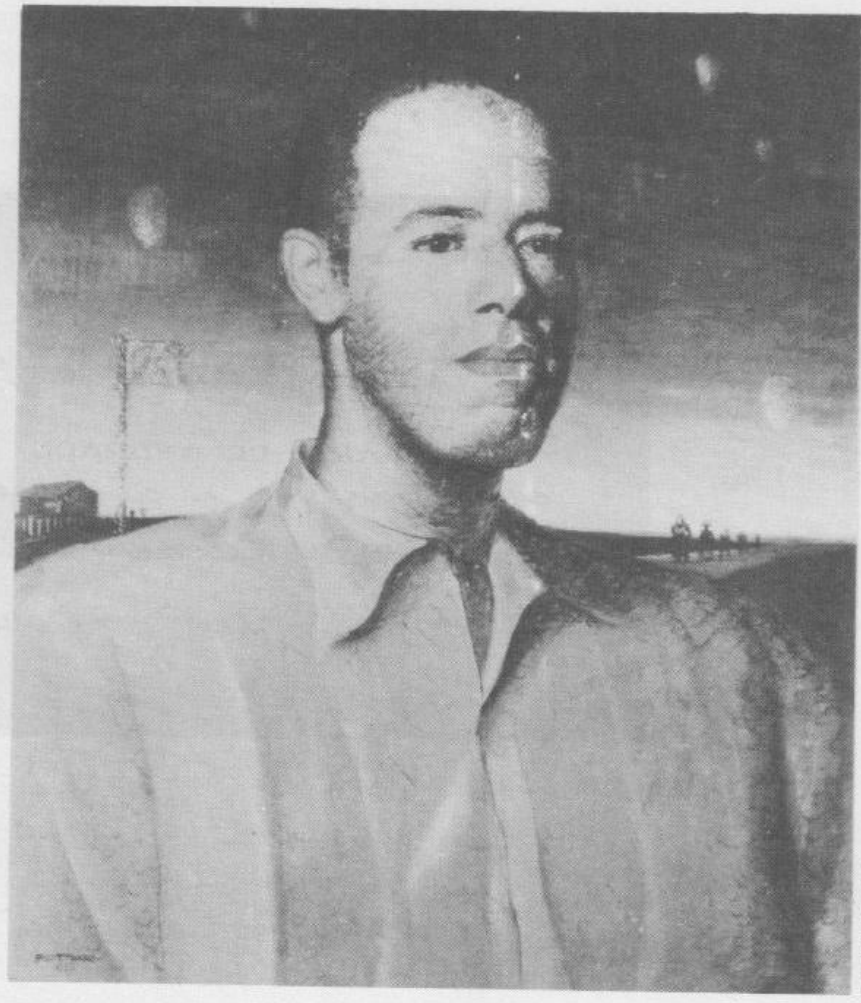

Mário de Andrade

Óleo de Cândido

Portinari - 1935

IEB - USP 


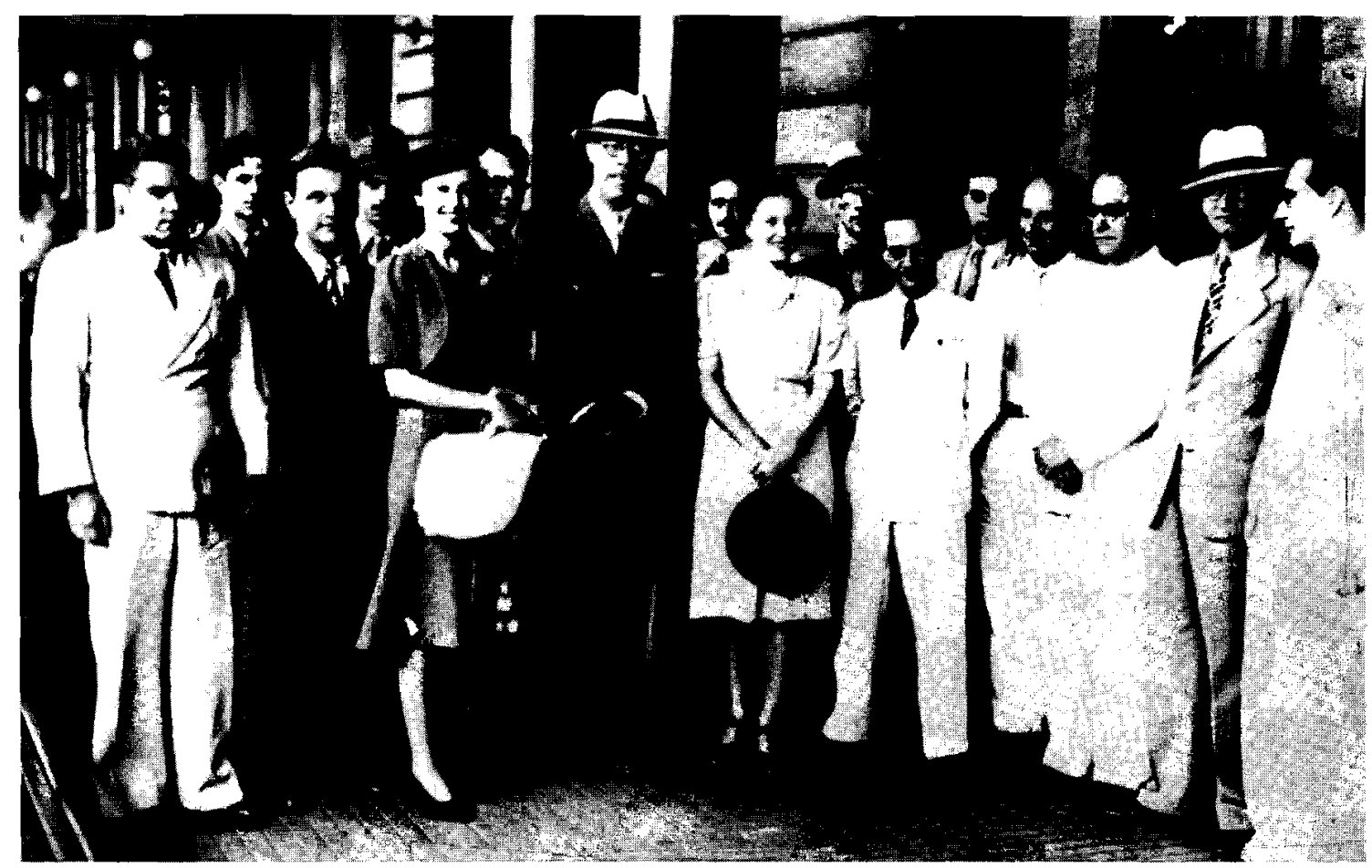

João Etienne Filho, João Camilo de Oliveira Torres, Aureo Fulgêncio, Murilo Miranda, Murilo Rubião, Yedda Braga Miranda, Guilhermino César, Mário de Andrade, Lúcio Rangel, Emy Andrade, Pedro de Castro, Marques Rebelo, Júlio Barbosa, João Alfhonsus, Baeta Viana, Cyro dos Anjos e José Carlos Lisboa

Gare da Central do Brasil - Belo Horizonte, 1939

(Acervo Murilo Rubião - CEL - UFMG)

Alfhonsus de Guimaraens

Filho, Hélio Pellegrino,

Mário de Andrade e Murilo

Rubião

Parque Municipal de Belo Horizonte, 1944

(Acervo Murilo Rubião CEL - UFMG)

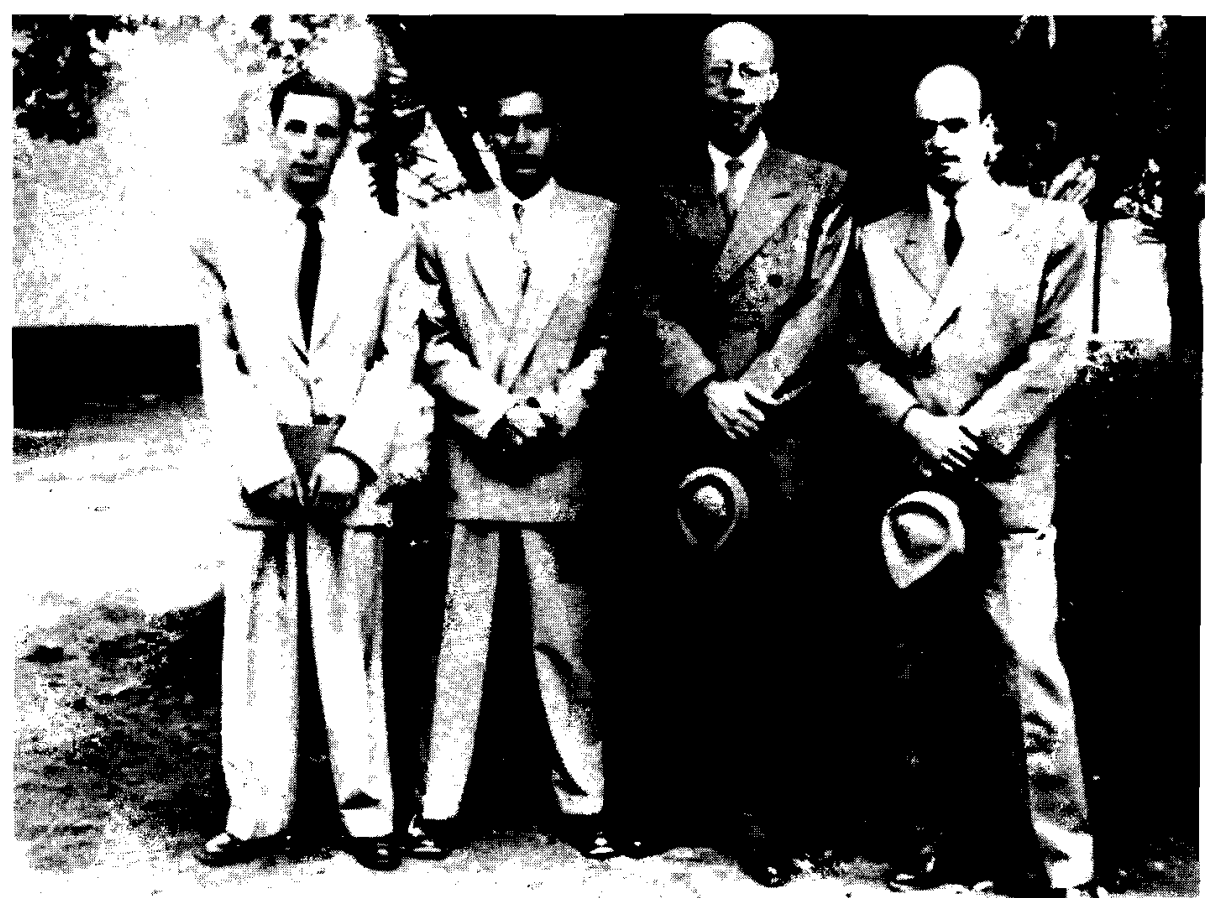


Disponível em http://www.letras.ufmg.br/poslit

DPantio 24-II-41

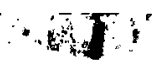

Hewrigreta grecridar

Infirm enter repriculhiacrolo a minher mida. Cainda tire que voltar ao hio, denfiger aparta omento, ver si afertaina men caro. se ćnucivnério e usua quentäo de paganentos eru atraro one ló far quase uon onés. Rqura eqtou arrumando mionthan coinan " tra reusuecar no traballo - expro gre scaquale suenswo ritsuo nais regellar de mida gen seuchre tive agri. Algune eariacai ficaram oné exto.

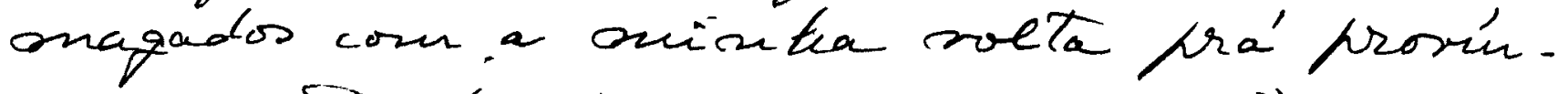

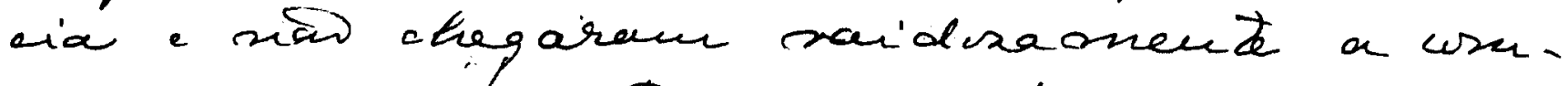
preender que on trocana ofrient'gio incornTertavelsuente omito suaiar da cafitale

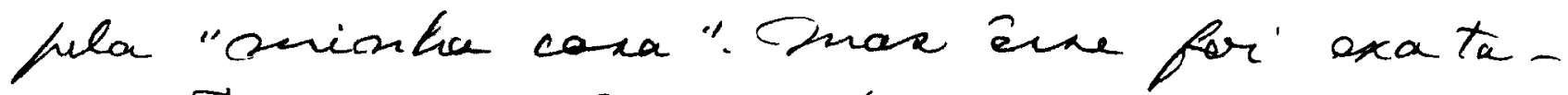
ment o caro. A miontru cara sue defiende, que sou, ghar smiue, omits dec frosido rale defejos. \& aobretudo a suinka cara me sur. rabiza, no mair vesto sentido diecta halausa. ate' quant a me tornar suain curomalmen.

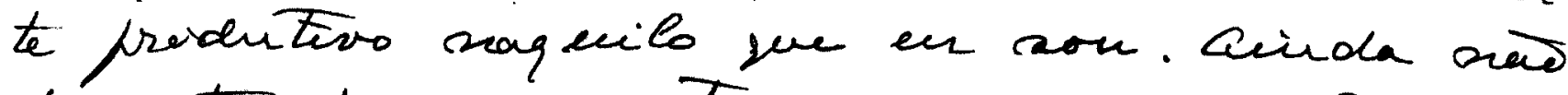
tive turpo de aenter sandades do Bio, sees. ta gutosen preocupacẫ de par as coine. no an engar, destruir guardedos imuteis ete., mas tertio certega que rou aentor nuitar aan.

Carta de Mário de Andrade a Henriqueta Lisboa - 24/I1/41 (Acervo Henriqueta Lisboa - CEL - UFMG) 


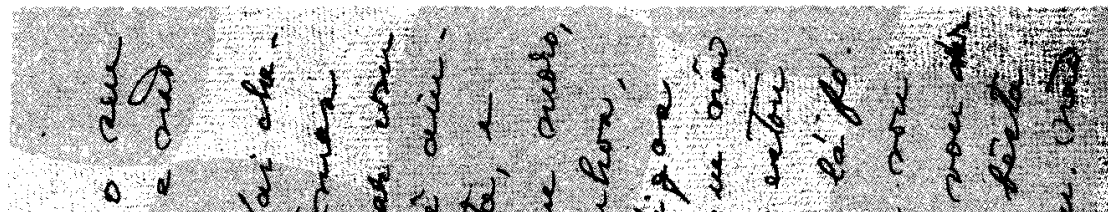

H

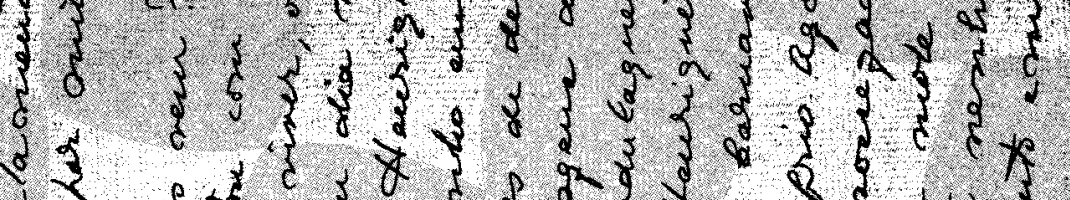

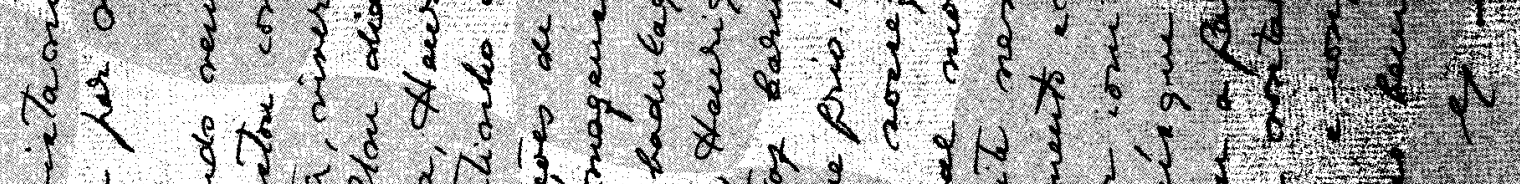

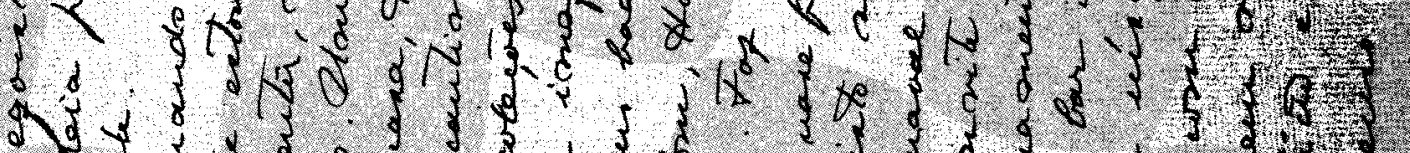

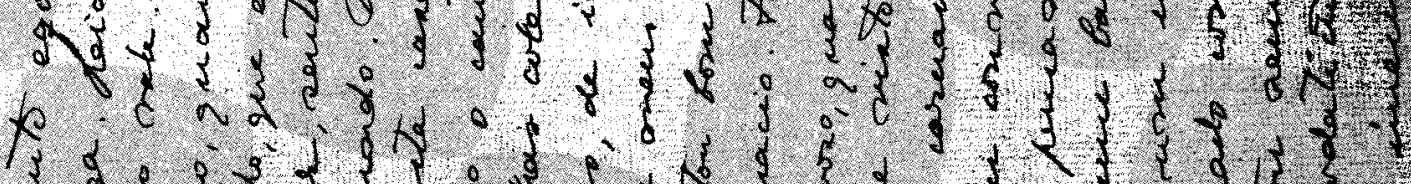

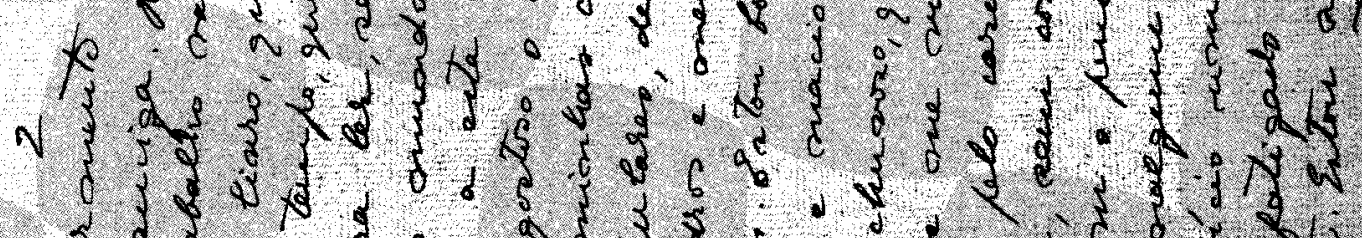

ช.

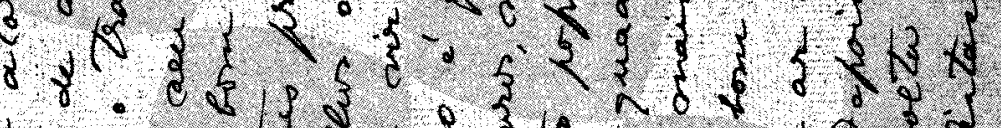

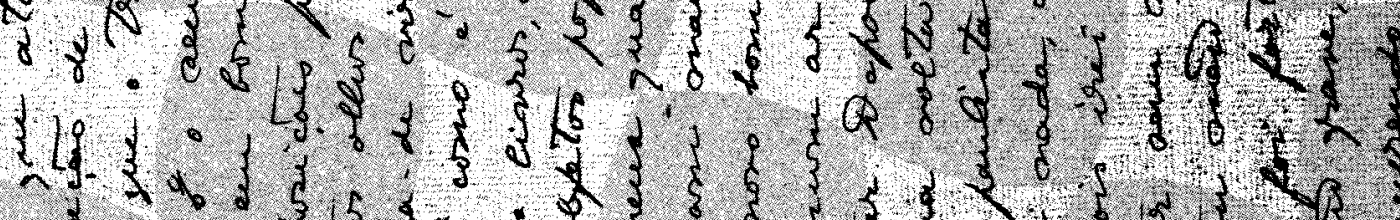

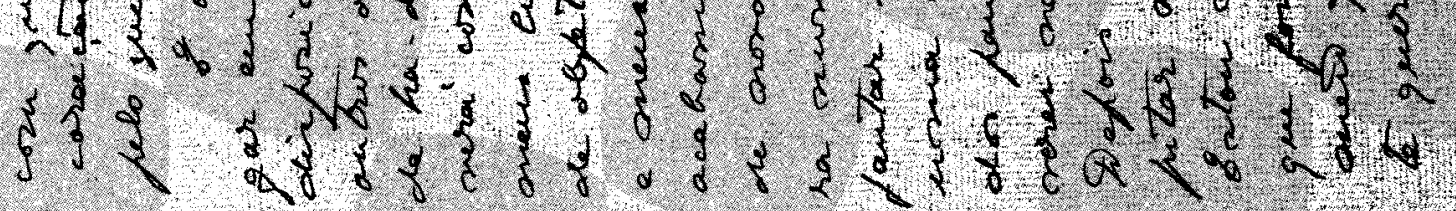

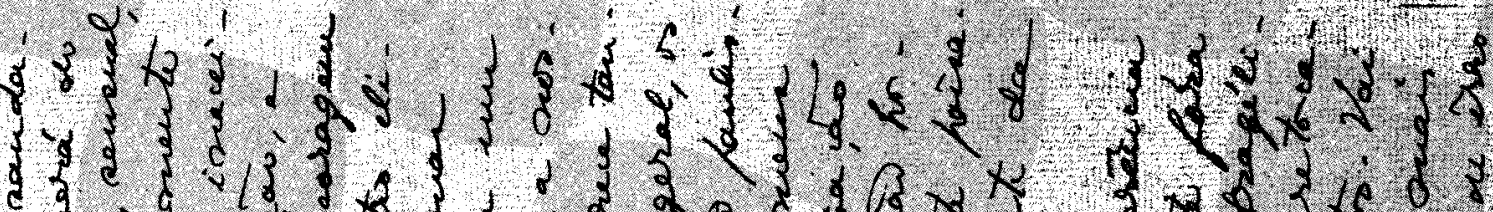
a d a

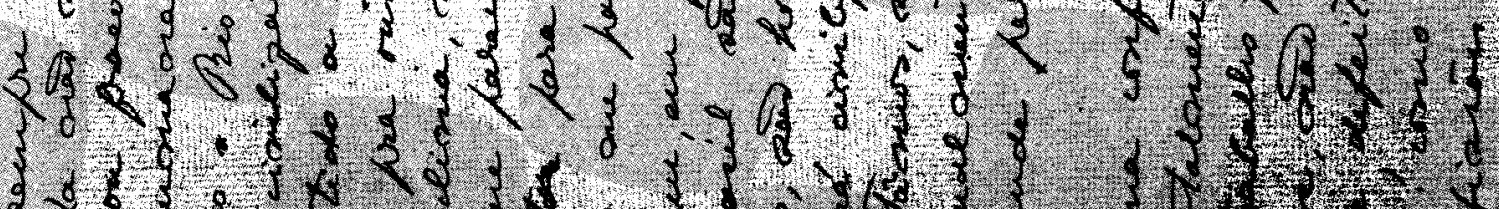

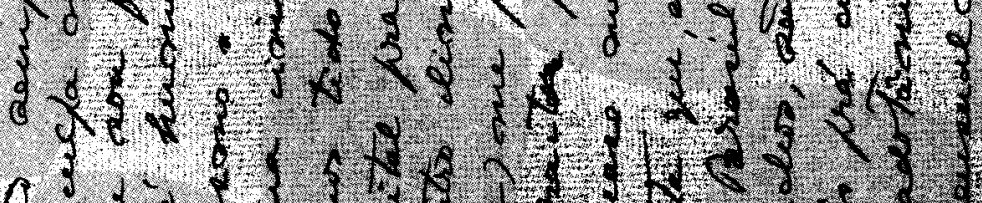

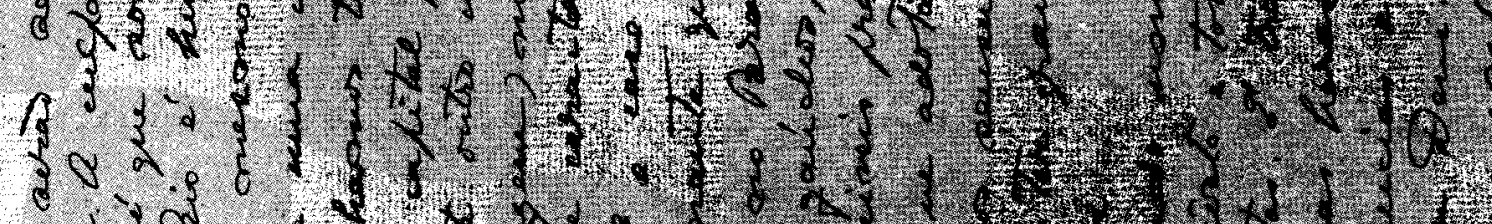

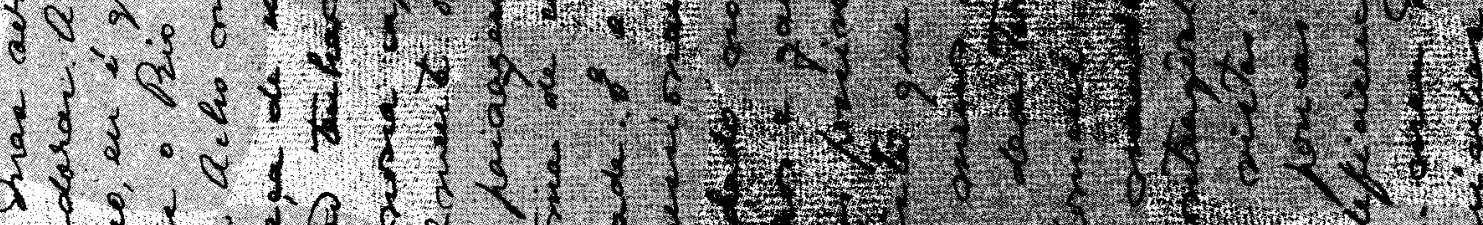

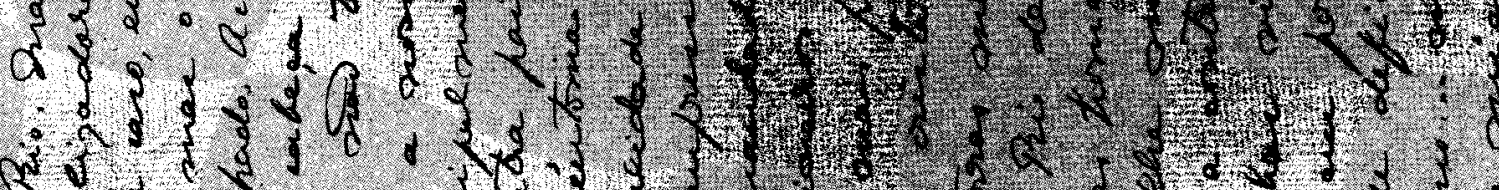

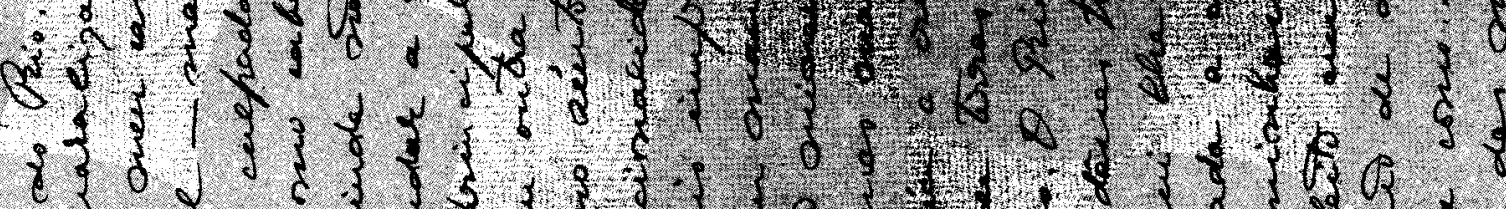

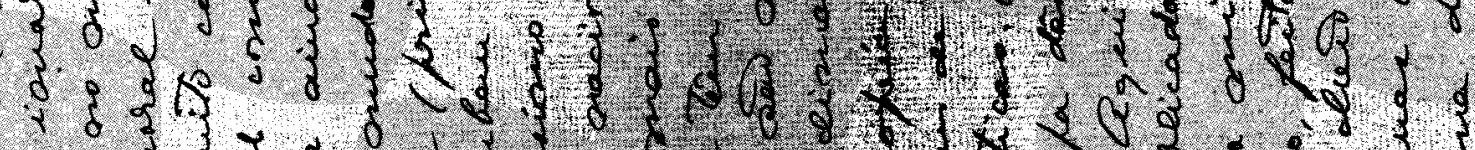

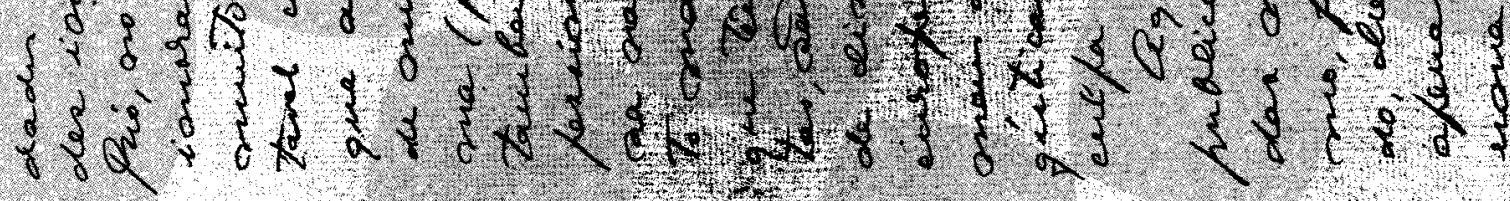


Disponível em http://www.letras.ufmg.br/poslit

1. Pande-1-T्र-44

Enurie. Ruariä

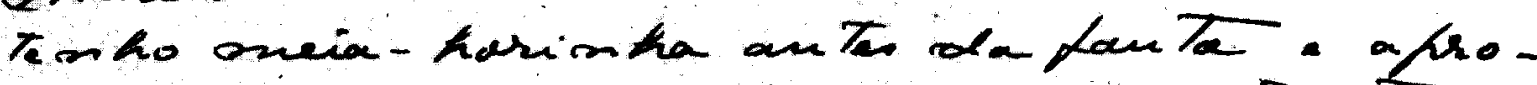

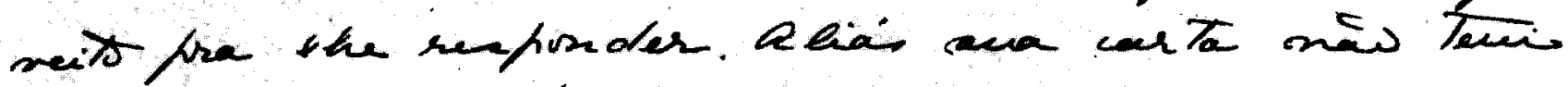

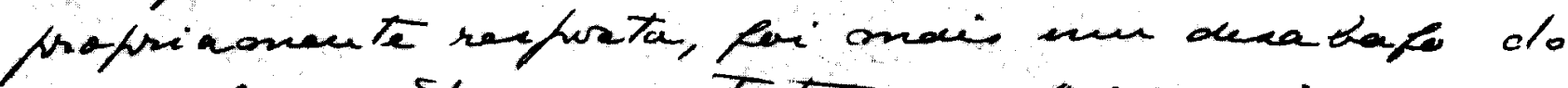

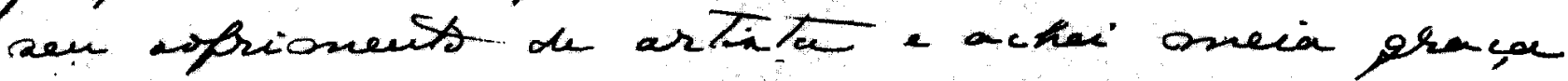
ovele. Si extimence a ace tado heara ma violionha e the sutaina agerele acalanto paciente do

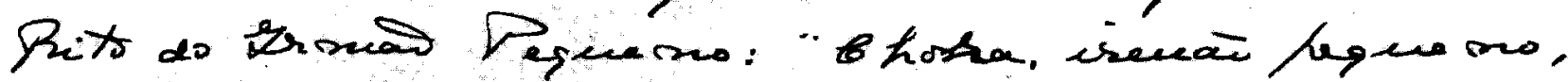

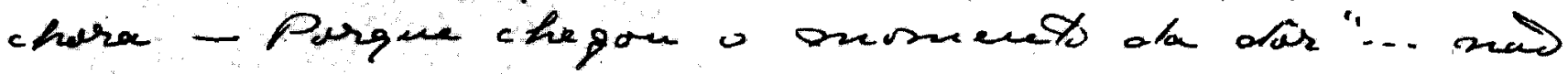
Pavalo anair.

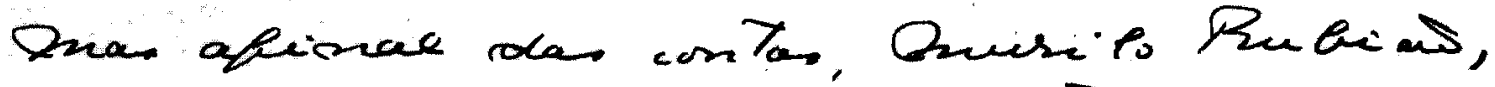
ond será ins menono, cofbimento de artis Ta como arte, a ferdra de topere provando a exis. Tindia do arter ta en roce ?... has da' a onedsiden do voler, en ari, inco defundir ate' de eteonecetos que indefendece do frophis artin Ta cinfalionen -

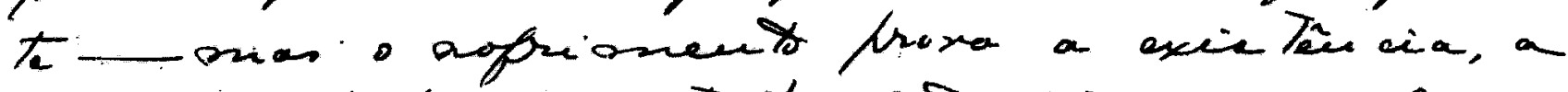

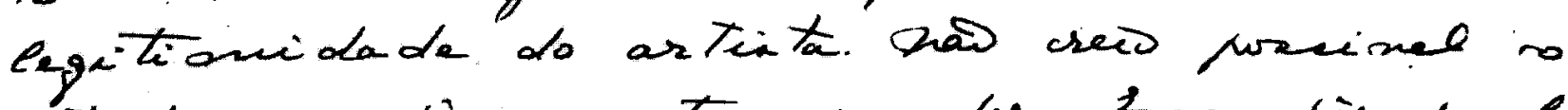

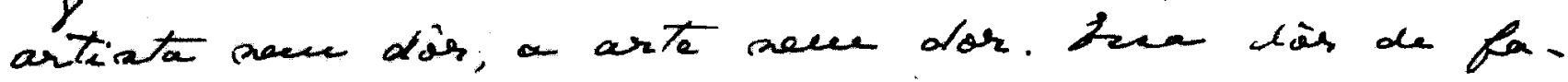

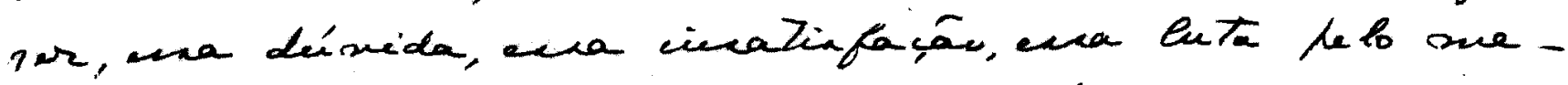

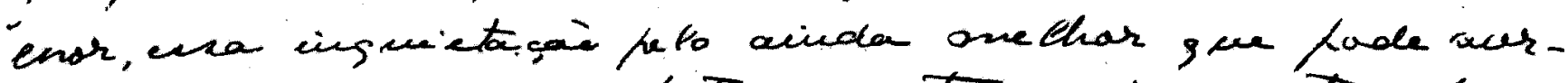

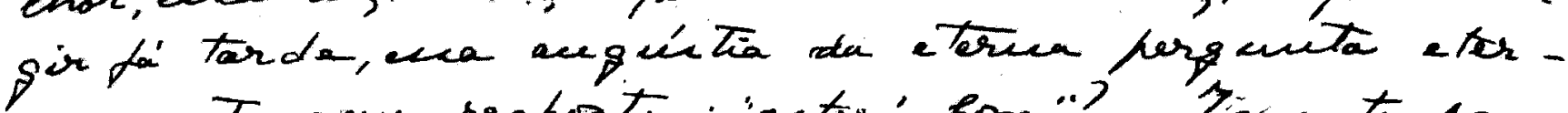

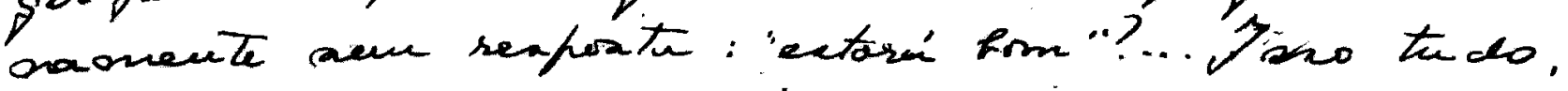
of wuta dev as ato expelinte de criar faj cena iscua-

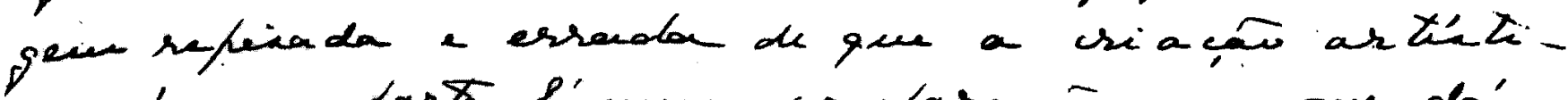

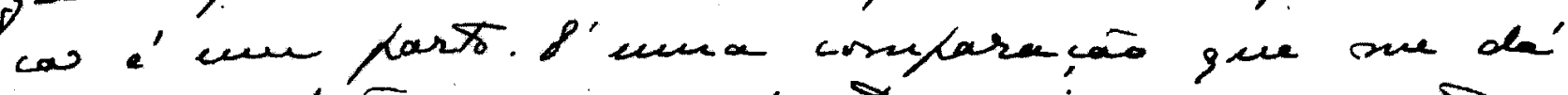

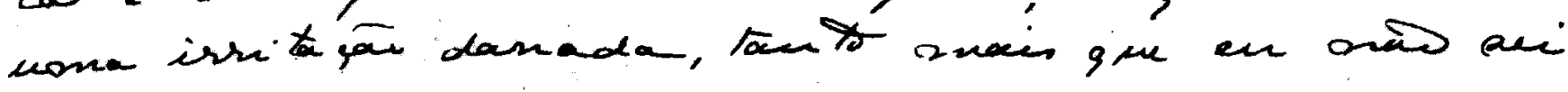

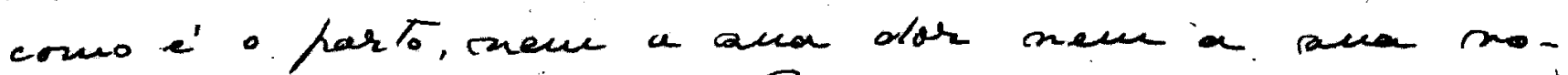
lípia. Alsma rey, leudo Bilthe que insinte sar si.

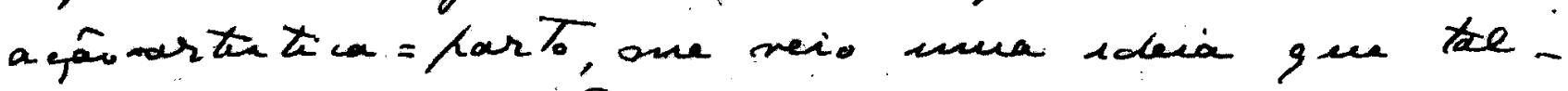
rey aefor diabo'lica. De refoute en ionagineri stre si

Carta de Mário de Andrade a Murílo Rubião - 5/IV/44 (Acervo Murilo Rubião - CEL - UFMG) 


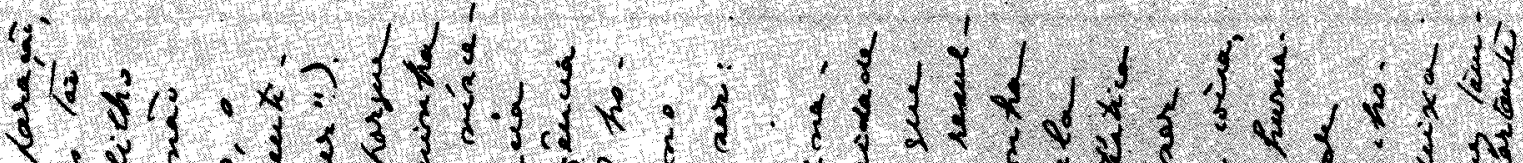

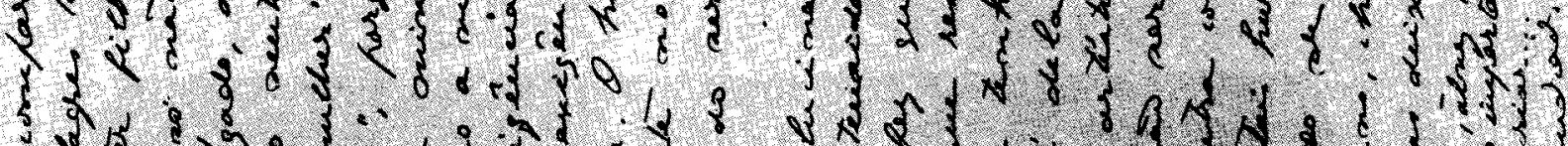
3. if 3 s.

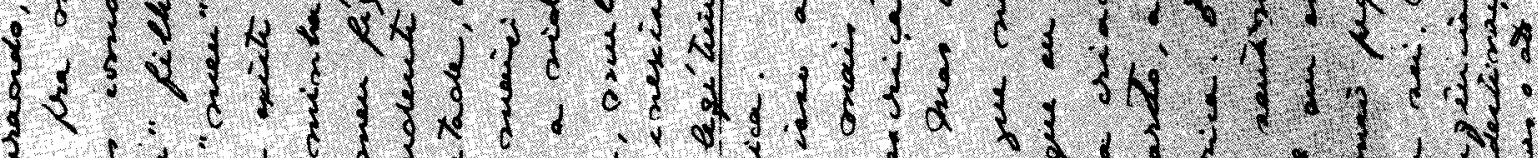

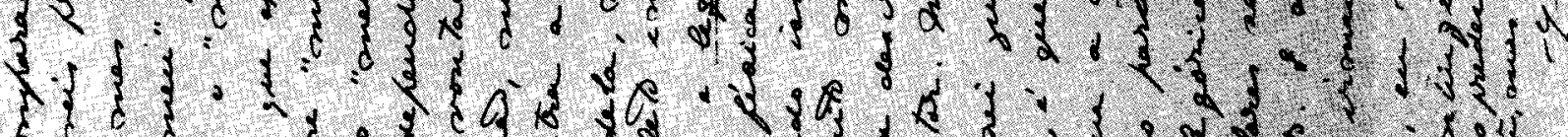

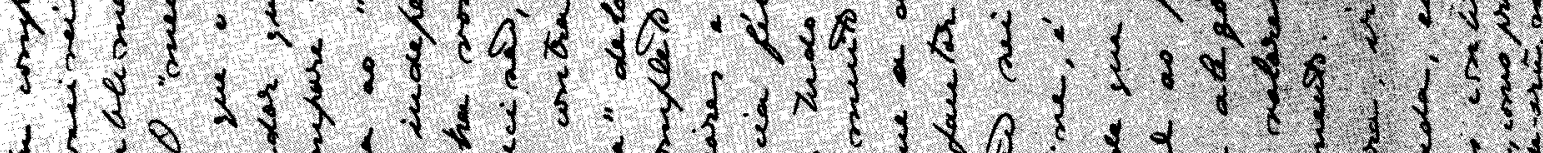

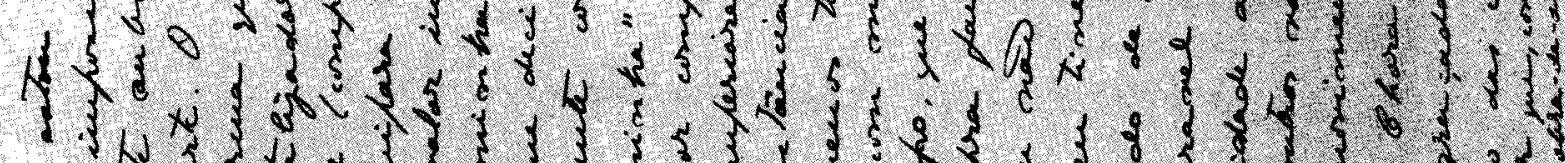
2月1 दूe y. की IJjo ik भी

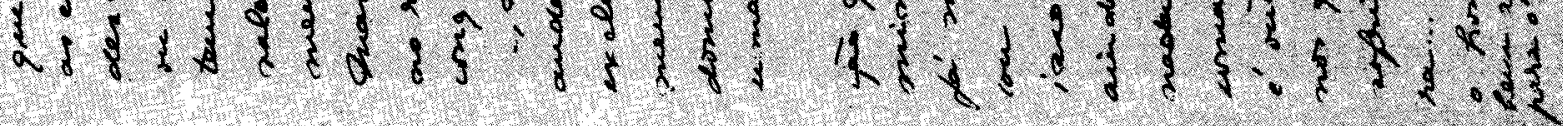

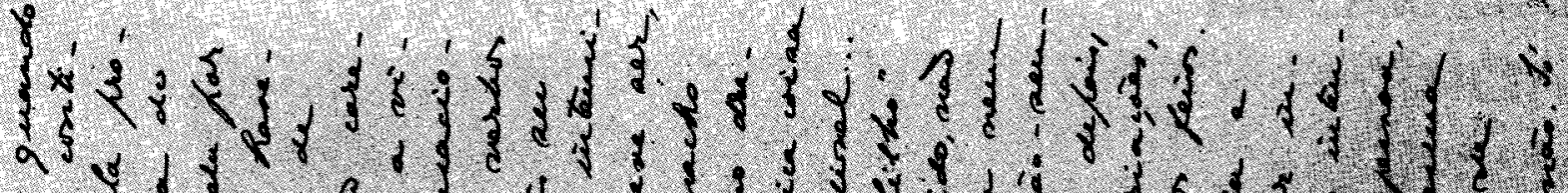
dq H. (1)

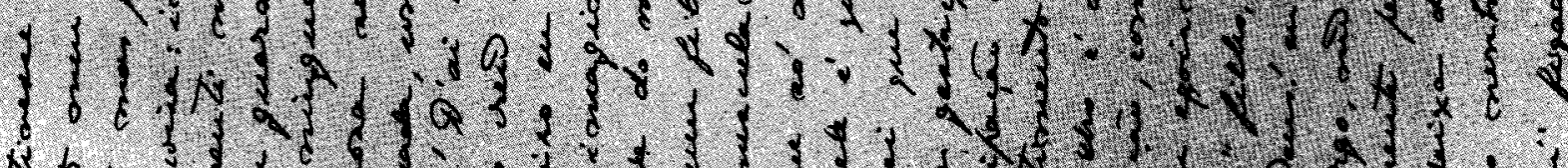

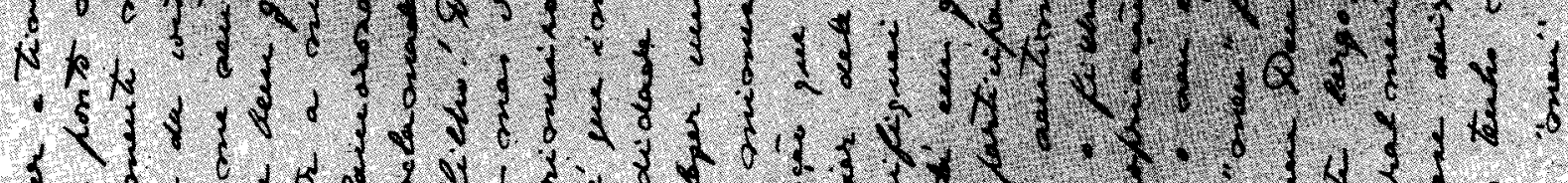
3.

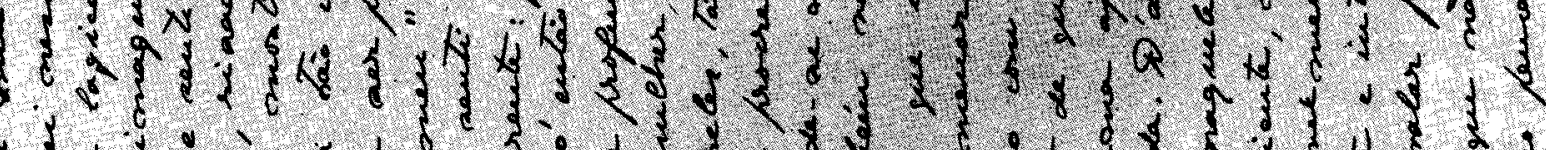

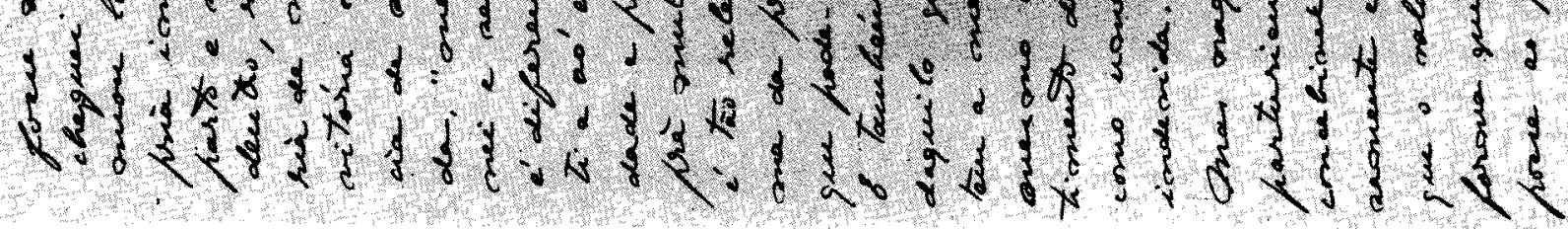




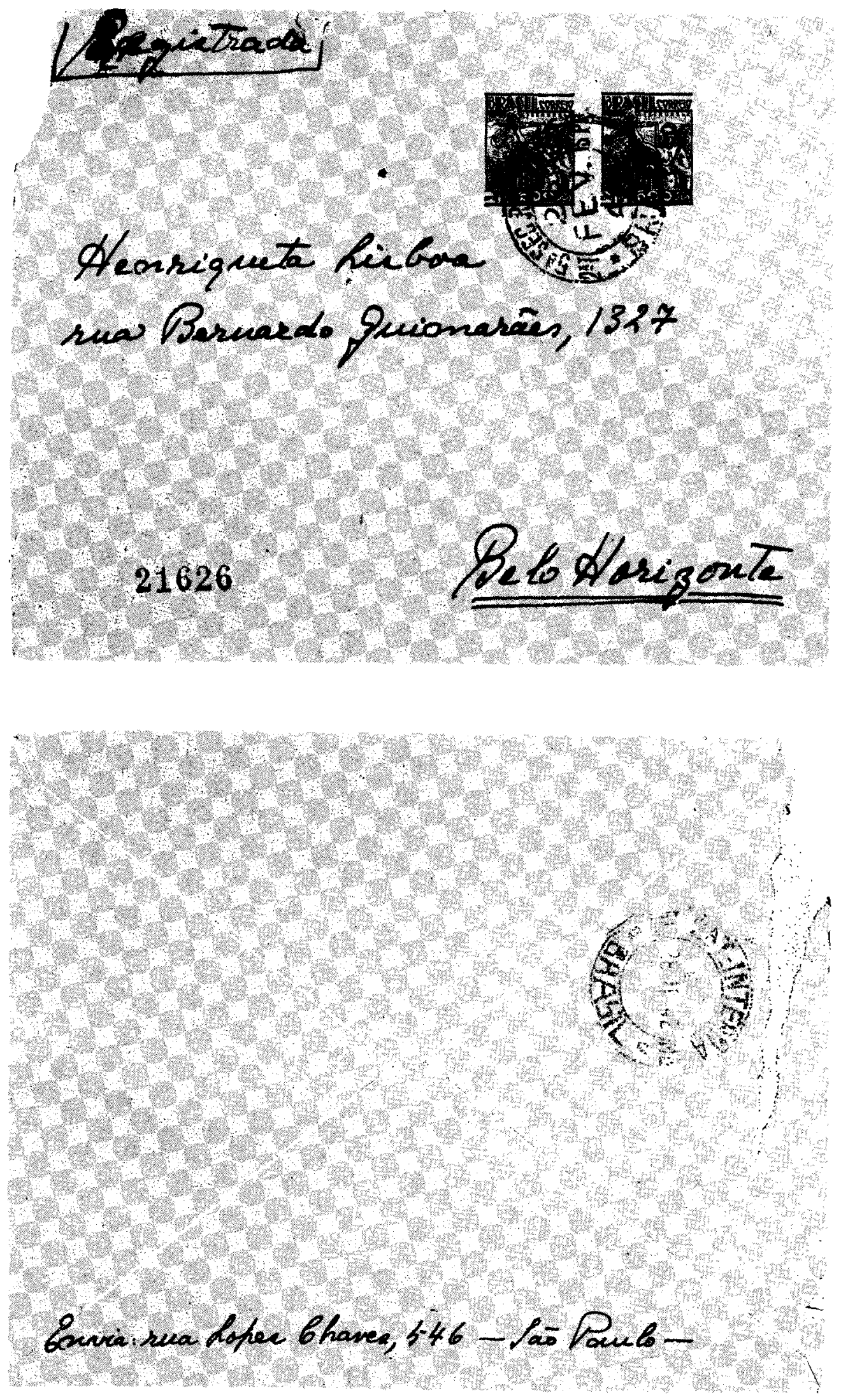

